\title{
Effects of Coating Populus nigra Wood with Nanoclay
}

\author{
Mostafa Emampour, ${ }^{\text {a }}$ Habibollah Khademieslam, ${ }^{\mathrm{a}, *}$ Mohammad Mehdi Faezipour, ${ }^{\mathrm{b}}$ \\ and Mohammad Talaeipour ${ }^{\mathrm{a}}$
}

\begin{abstract}
This study evaluated the effects of coating Populus nigra wood with nanoclay by dip-coating and spin-coating. The samples were coated with nanoclay in concentrations of 3,5 , and $7 \%$, and the products were compared with Abies alba wood as standard control for the morphological and moisture properties. Zycosil was also added into nanoclay as an adaptive material. The crystalline and morphological structures were investigated by X-ray diffraction (XRD) and scanning electron microscopy (SEM). Performance parameters including water absorption, contact angle, density, and flexural resistance were investigated. Water absorption was decreased, but the density, flexural resistance, and contact angle were increased in nanoclay treatments compared with the $P$. nigra control group $(P<0.05)$. The best performance properties were observed at a concentration of $7 \%$. In sum, the concentration of $7 \%$ nanoclay in dipcoating decreased water absorption by $250 \%$ and increased water angle by $150 \%$, density by $113 \%$, and flexural resistance by $145 \%$ compared to $P$. nigra control group.
\end{abstract}

Keywords: Contact angle; Nano-clay; Dip-coating; Spin-coating; Water absorption

Contact information: a: Department of Wood and Paper Science Technology, College of Natural Resources and Environment, Science and Research Branch, Islamic Azad University, Tehran, Iran; b: Retired Professor, Department of Wood and Paper Science and Technology, Faculty of Natural Resources, University of Tehran, Iran; *Corresponding author: hkhademieslam@gmail.com

\section{INTRODUCTION}

Wood has many advantages, and it is used in different fields and industries. Wood has a sustainable and renewable structure that can be simply used (Petric 2013). However, wood is sensitive to water due to its capillary porous and hydrophilic nature (Wegner et al. 2012). It has other disadvantages such as sensitivity to microbial degradation and flammability (Mantanis and Papadopoulos 2010). Different methods such as acetylation, polymerization, and adding flavonoids are used for improving wood structure and resistance to moisture, but these methods are not efficient (Chang et al. 2015). Nanoparticles have attracted attention for this purpose.

Nanoclays are fine particles and have sheet-form structures (Mandal et al. 2020). Adding nanoclay into polymeric structures as coating has been found to improve the mechanical, thermal, and physical properties of wood (Ha et al. 2010; Hwang et al. 2010; Zainuddin et al. 2010). Nanoclay as coating creates cross bonds with other materials, and it improves the morphological, strength, flexural, mechanical, and thermal stability properties (Hazarika and Maji 2014; Wang et al. 2016). Anwar et al. (2019) investigated the effects of nanoclay contents on the properties of water-based coating and showed that abrasion resistance of the coatings was improved when $2 \%$ nanoclay was added. Landry et al. (2010) investigated mechanical and optical properties of clay-based nanocomposites coatings for wood flooring and showed that clay dispersion influenced mechanical and optical properties of wood. Inorganic fillers such as nanoclay distribute the stress between matrix and filler.

Zycosil is an organosilane material that can be used as a base structure and is connected to nanoclay and converts it to hydrophobic structures. Loading nanozycosil 
into medium density fiber boards decreased their permeability to water and gas (Taghiyari 2013). Different methods are used for coating materials on the surface, such as spin-coating and dip-coating. Dip-coating is an old method for depositing a substrate, while spin-coating is used for homogenous distribution of materials on a surface (Scriven 2011).

Populus nigra wood has been used for a long time in Iran, and western regions, and it has many uses (Alimohamadi et al. 2012). Nanoclay can be bound with zycosil on wood surfaces, where it fills pores and improves physical properties. Because $P$. nigra has lower performance properties than Abies alba wood, it was assumed that nanoclay can penetrate the wood structure and improve its properties. Nanoclay is commonly added into nanocomposites woods, but no research studies have considered its inclusion into massive wood, such as $P$. nigra and Abies alba. In addition, study of a combination of nanoclay and zycosil as coating on wood has not been conducted. Spin-coating and dip-coating are not common methods on wood. In this work both methods, for first time, were used on massive wood. This study aimed to evaluate the effects of coating $P$. nigra wood with nanoclay and zycosil in different concentrations on mechanical properties of the wood.

\section{EXPERIMENTAL}

\section{Materials}

Eighteen $P$. nigra wood samples were prepared from Kurdistan province with radial cuts. The wood samples were prepared with standard dimensions of $30 \times 20 \times 5$ mm, as denoted by ASTM 1037-D/D0143-94 (1999). Nanoclay and Zycosil were obtained from Merk (Darmstadt, Germany), and Zaydex (Pan, India), respectively.

\section{Treatments}

To prepare the treatments, dip-coating and spin-coating methods were used in the concentration of 3, 5, and 7\% for P. nigra samples. Zycosil (20:1 w/w) was added into nanoclay as an adaptive material. In addition, three samples $P$. nigra and three samples A. alba were considered as controls. For all the tests, all the samples $(n=24)$ and three samples for each concentration were used. Initial moisture was $85 \%$ in fresh samples and moisture was $12 \%$ in final samples for the tests.

\section{Methods}

Dip-coating

A dip-coating method was conducted based on Archimedes' law. The prepared samples were dip-coated in a cylindrical polymeric container for 4 days. To remove contaminants, the container was washed by acetone and distilled water. Following saturation and coating, the samples were kept for 30 days to be reached a balanced moisture (12\%).

\section{Spin-coating}

Wood samples were prepared, cleaned, and positioned into a T.D.I.90.m4 apparatus (Modern Technology Co., Tehran, Iran). The prepared solutions at concentrations of 3,5, and 7\% were used and the samples were coated at 360 to 1500 rpm for $60 \mathrm{~s}$ by apparatus nozzle. After coating samples and saturation, the samples were placed in a standard condition to be obtained an equilibrium moisture for 30 days. Physical and mechanical tests were conducted on samples. Smaller samples rapidly obtained the balance. 


\section{Water absorption}

To assess water absorption, the samples were first weighed on a scale (S313 TE model, Sartorius), and the samples were weighted after 30 days. To measure absorption, the standard method ASTM C128-04a (2004) was used.

\section{Contact angle}

A KSV-CAM200 apparatus (KSV Instruments Ltd, Helsinki, Finland) was used to assess contact angle with ASTM D7334-08 (2013). Sessile drop test was used to investigate the contact angle. The system was equipped with a charge-coupled device camera. The contact angle was measured after a droplet of $4 \mu \mathrm{L}$ on the samples surface. The samples were investigated from right and left locations.

\section{$X$-ray diffraction (XRD) and scanning electron microscopy (SEM)}

To analyze crystallinity and morphology, XRD (SEFER, S3003PTS, Germany) by X-ray tube and SEM (LEO 440i, LEO, England) by gold-coating method were used, respectively.

\section{Density}

To assess density, an apparatus produced by Rad Way Company (YDK04 model-Germany) was used. To assess density, Density and Specific Gravity ASTM D792, ISO 1183 was also used. To determine volume, ethanol 99\% was added into a beaker as initial volume and the sample was dipped into a beaker and final volume was calculated.

\section{Flexural test}

To assess flexural resistance, the ASTM E290 standard and an apparatus made by Torsee Company (MFG.VO20A21 model, Japan) were used. To investigate flexural resistance, the samples were placed on a plate and gradually pressed.

\section{Data analysis}

SPSS software (version 23) was used for analysis of variance (ANOVA). The means were compared by Duncan's test at level of 0.05 .

\section{RESULTS AND DISCUSSION}

\section{Water Absorption}

The water absorption values in P. nigra and A. alba control samples were 2.50 \pm 0.30 and $0.70 \pm 0.10 \%$, respectively (Fig. 1). There was a significant difference between samples $(P<0.05)$. Thus, wood structure and their surface extractives had a significant effect on water absorption. A. alba wood has a gum form (Wegner et al. 2012) that might prevent water absorption.

Coating with nanoclay progressively decreased water absorption, so that the lowest and the highest water absorption were found for concentrations of 7\% (0.95 \pm $0.1)$ and $3 \%(1.29 \pm 0.2)$ for the dip-coating method. The results for spin-coating showed that increased nanoclay decreased water absorption, so that values were $1.32 \pm$ $0.10,1.21 \pm .10$, and $0.95 \pm 0.08$ for the concentrations of 3,5 , and $7 \%$, respectively. These results suggest that nanoclay prevents water absorption and are in accordance with previous reports (Alamri and Low 2013; Devi and Maji 2013; Hosseyni et al. 2014). Moreover, nano-based wood coating can provide exterior protection such as UV 
resistance and hydrophobicity for wood (Teng et al. 2018). Nanoclay creates a tortuous pathway, and prevents water entrance.

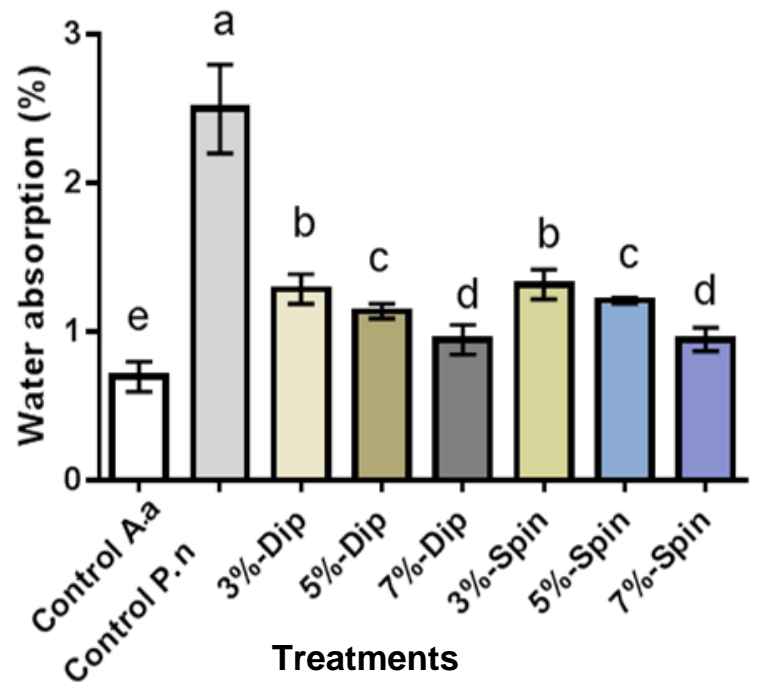

Fig. 1. Water absorption (\%) in A. alba (A.a.) and P. nigra (P.n.). Superscripts (a-e) show significant differences among groups

The results also showed that water absorption was significantly lower in the samples treated with nanoclay in both methods compared with the P. nigra control. The $P$. nigra control had more pores, but the treatment with nanoclay created tortuous pathways. A. alba wood is covered with gum that fills pores without any treatment. Increasing concentration decreased water absorption. Certainly, both methods prevented the bonding of hydrogen molecules in the wood structure, and both methods create complex pathways. In sum, water absorption was decreased in both methods, and the highest reduction was observed in highest concentration of nanoclay. Water absorption was not different between dip-coating and spin-coating, which means that both methods can have similar effects on water absorption. In sum, a bond between nanoclay and zycosil creates a structure that decreases water absorption.

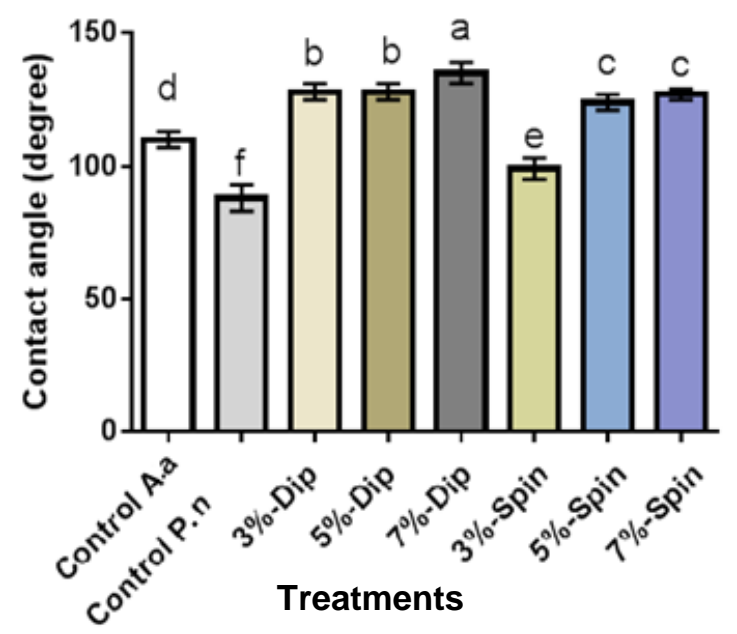

Fig. 2. Contact angle results in different treatments. Superscripts (a-f) show significant differences among groups 


\section{Contact angle}

The results for contact angle are shown in Fig. 2. The values were $88.0 \pm 9.0$ and $110.0 \pm 3.0$ in $P$. nigra and A. alba, respectively. The contact angle was significantly higher in $A$. alba samples, indicating that water absorption was lower in A. alba. The results showed the angles that formed in $P$. nigra samples were oval, and in semi-circle form. However, the angles were a complete circle form in A. alba samples. The difference between P. nigra and A. alba may be associated with their structures.

In $P$. nigra samples treated with nanoclay via dip-coating, the contact angle values for treatments of 3,5 , and $7 \%$ were $128.0 \pm 3.0,128.0 \pm 3.0$, and $135.0 \pm 2.0$, respectively. The results showed a non-significant difference between treatments of 3 and $5 \%$, but it was significantly higher in the $7 \%$ treatment. In spin-coating method, the values were $99.0 \pm 4.0,124.0 \pm 3.0$, and $127.0 \pm 2.0$ for treatments of 3,5 , and $7 \%$, respectively. The contact angle was higher in the 5\% and 7\% treatments than in the $3 \%$ treatment.

Similar to findings for water absorption, increasing nanoclay particles increased the contact angle. Kamal et al. (2009) treated polymer surface with nanoclay and showed that increasing nanoclay increased contact angle. They modeled smoothness of the polymer surface and did not find a relationship between smoothness and contact angle. Zaidi et al. (2019) treated nanocomposite membranes and showed that adding nanoclay increased contact angle. Contact angle was significantly higher in woods treated with nanoclay particles compared with the $P$. nigra control. The contact angle was $88^{\circ}$ in control $P$. nigra, which shows its hydrophilic properties. A. alba wood had better structure, but the use of dip-coating and spin-coating of nanoclay particles in the concentrations of 5 and $7 \%$ improved the contact angle. In sum, nanoclay and zycosil creates bonds that increase the contact angle of water.

\section{Density}

Density is used for assessing void spaces in wood structure, and it has a positive relation with water absorption. The data for density in Fig. 3 show that values were $0.425 \pm 0.01$, and $0.520 \pm 0.02 \mathrm{~g} / \mathrm{cm}^{3}$ for $P$. nigra, and A. alba samples, respectively. The data show that water absorption was significantly lower in $P$. nigra samples compared to A. alba samples, which indicates lower void space in A. alba samples. It is natural that water fills void space, and it decreases density.

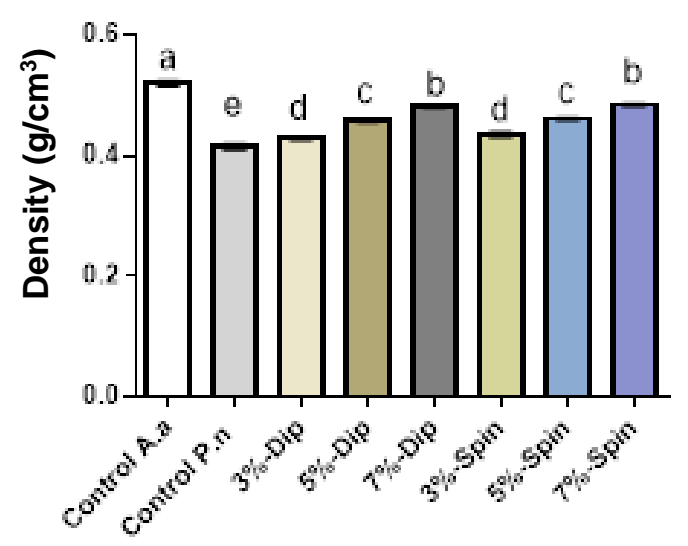

Treatments

Fig. 3. Density in different treatments. Superscripts (a-e) show significant differences among groups 
The data for the dip-coating method showed that values for the treatments of 3, 5 , and $7 \%$ were $0.438 \pm 0.02,0.457 \pm 0.01$, and $0.482 \pm 0.02$, respectively. The data showed a linear relation between nanoclay particle concentration and density, so that increasing nanoclay particle concentration increased density. The results for spincoating showed that values were $0.435 \pm 0.03,0.461 \pm 0.02$, and $0.485 \pm 0.03$ for the concentrations of 3,5, and 7\%, respectively. Ashori and Nourbakhsh (2011) showed that nanoclay fills micropores, and this work does not allow water penetration to deeper parts, and increases wood density. The results for water absorption showed that increasing nanoclay concentration in combination with zycosil decreased water absorption. Seemingly, nanoclay particles are connected to zycosil, and prevented water penetration, and increased density. Increasing nanoclay concentration may slow down the flow of water into the wood so that it swells less during the immersion period. The results showed that the highest and the lowest densities were observed in A. alba, and $P$. nigra controls, respectively. All the wood samples treated with nanoclay particle showed higher density compared to $P$. nigra control, but the treated samples showed lower density compared to $A$. alba samples. There was no significant difference observed between similar concentrations for the two methods.

\section{Flexural Strength Test}

The results for flexural strength are shown in Fig. 4. The results showed that flexural strength values were 16.65 and 8.85 for $A$. alba and $P$. nigra samples, respectively. The results showed higher resistance to flexure in A. alba samples; this result might be attributed to their structures. The values were 10.13, 11.63, and 12.39 for the concentrations of 3,5 , and $7 \%$, respectively. This means that adding nanoclay particles progressively increased flexural strength. The results for spin-coating showed that flexural strength was $8.17,10.63$, and 11.13 for the concentrations of 3,5 , and $7 \%$, respectively. The results showed that $A$. alba control samples had highest flexural strength compared to other groups. The lowest flexural strength was observed in $P$. nigra samples. A linear relation was observed between nanoclay concentration and flexural strength in dip-coating method.

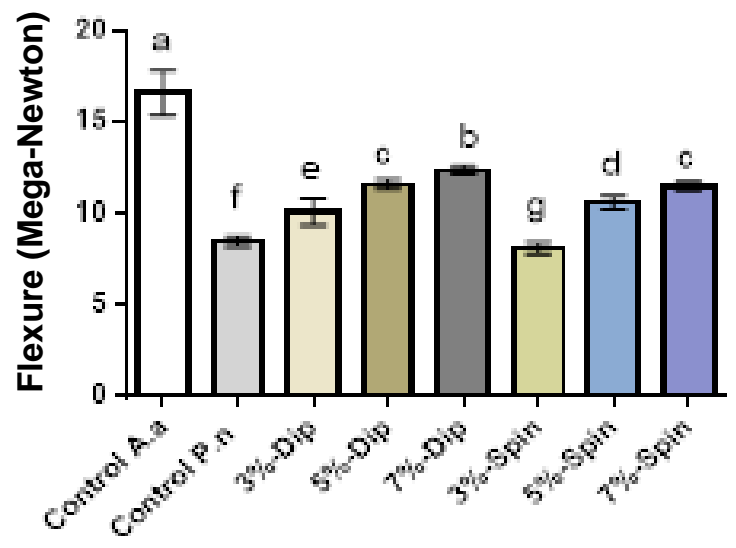

Treatments

Fig. 4. Density in different treatments. Superscripts (a-e) show significant differences among groups 
XRD

The XRD results for control treatments are shown in Fig. 5. The results showed small peaks in the samples. There was no significant difference between control treatments for the two wood types.

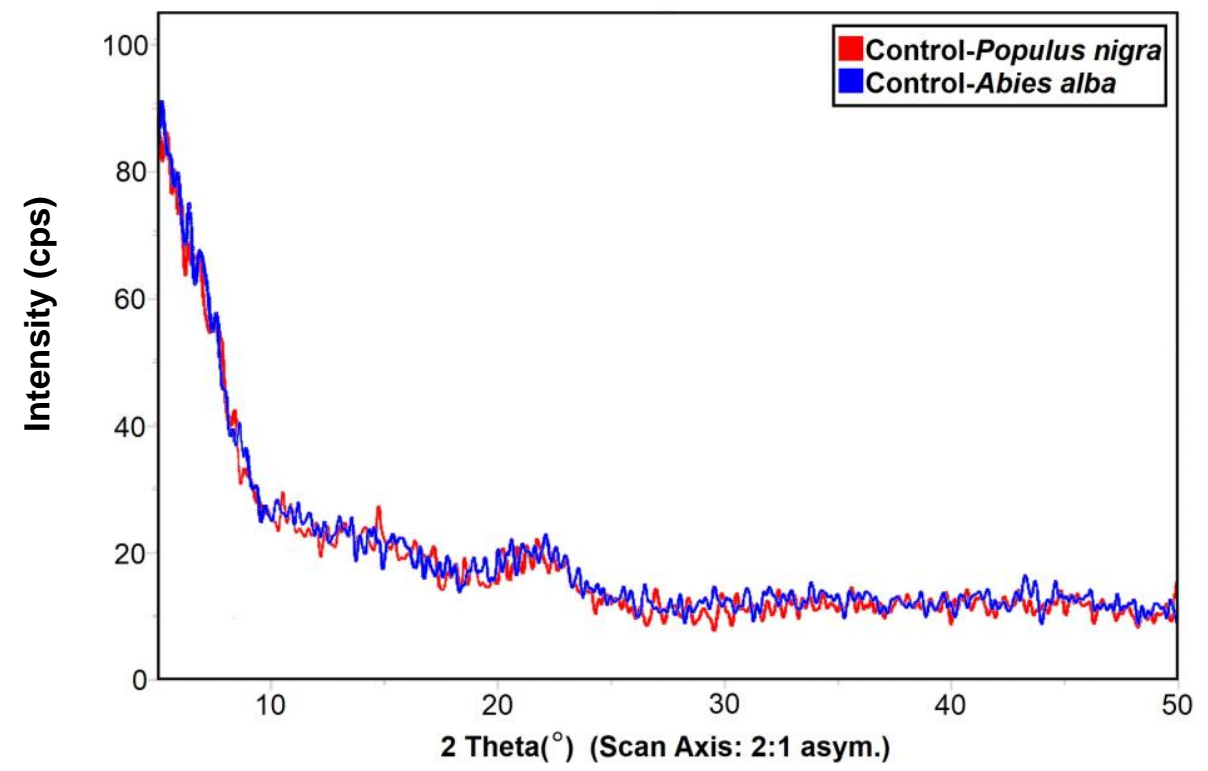

Fig. 5. XRD results in control samples of $P$. nigra and $A$. alba

For the dip-coating (Fig. 6) and spin-coating (Fig. 7) methods, peaks were observed at $22.12^{\circ}$ for all concentrations. There was no peak at $22.12^{\circ}$ in the control treatments. This result indicates crystalline production and bond between nanoclay and zycosil with $P$. nigra wood. Conversely, Islam et al. (2013) showed peaks at $40^{\circ}$ and $70^{\circ}$, indicating nanoclay crystals. A comparison of dip-coating and spin-coating exhibited a higher intensity peak at the 5\% concentration for the dip-coating method, while higher intensity was observed in the concentration of $3 \%$ for the spin-coating method.

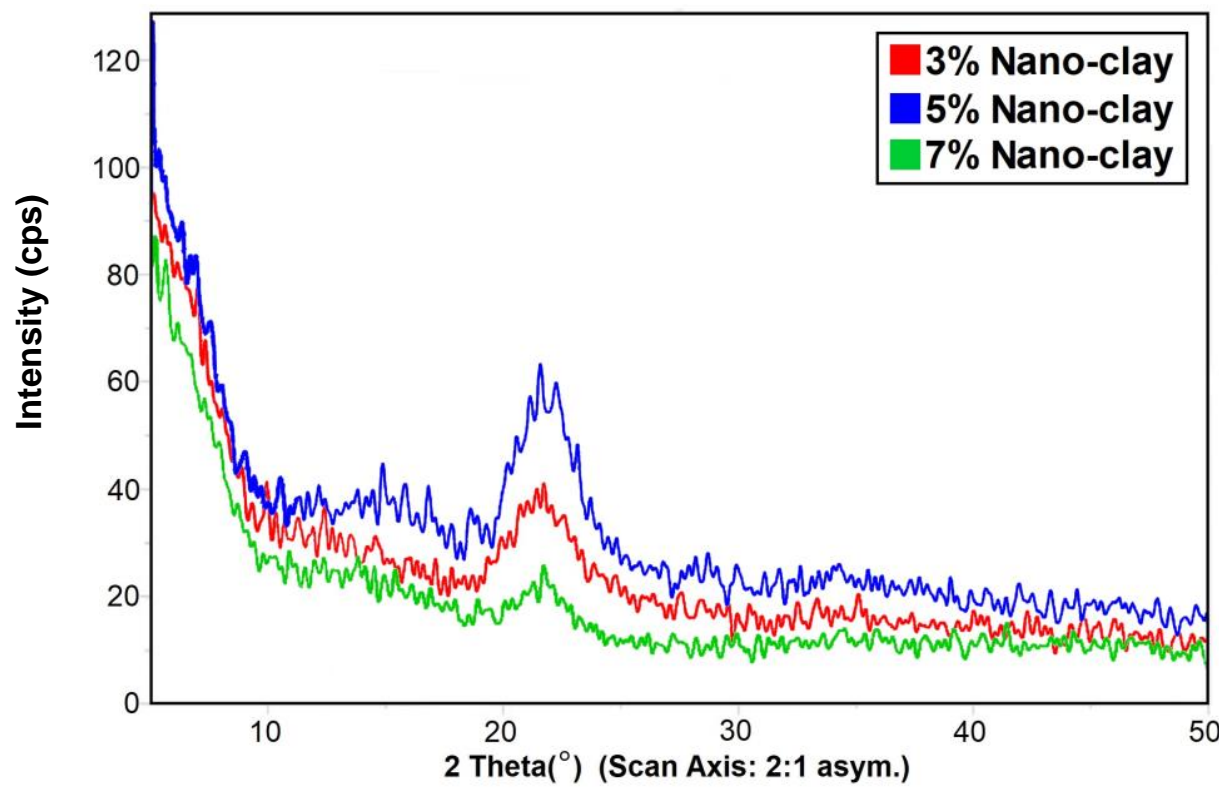

Fig. 6. XRD of $P$. nigra samples coated with 3,5 , and $7 \%$ nanoclay via dip-coating 


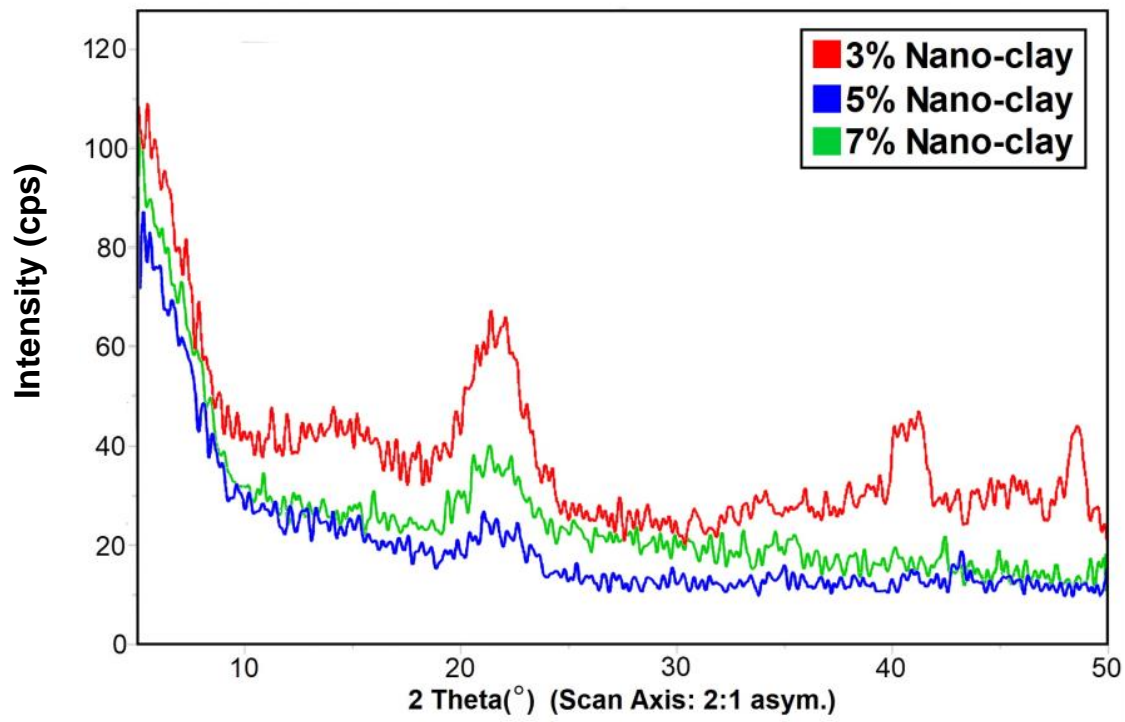

Fig. 7. XRD of $P$. nigra samples coated with 3,5 , and $7 \%$ nanoclay via spin-coating

\section{Scanning Electron Microscopy}

The results for SEM are shown in Fig. 8. Internal bonds and connections were observed in both woods. There were some spaces in A. alba wood, but it did not show differences with $P$. nigra wood.

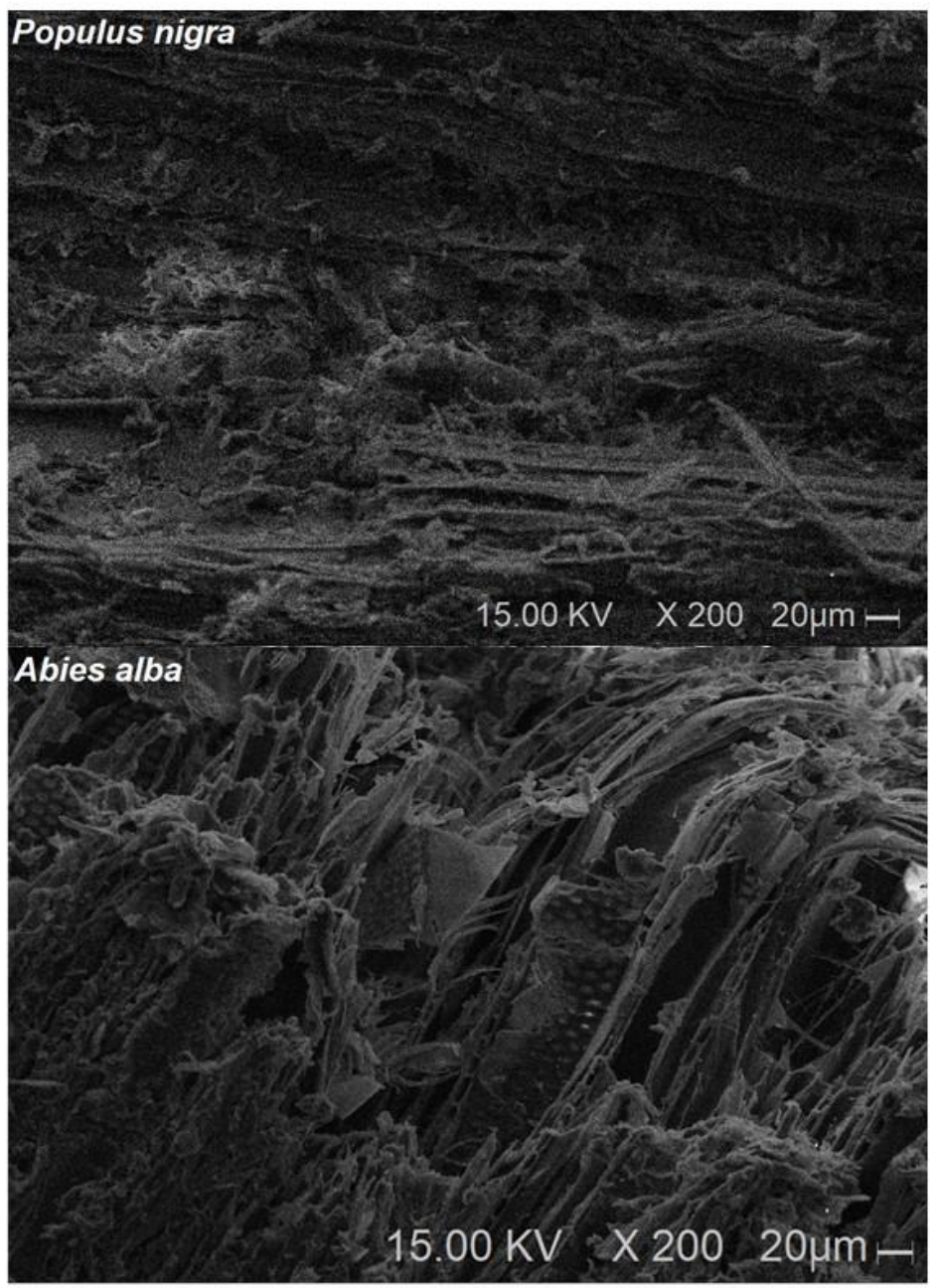

Fig. 8. SEM of $P$. nigra and $A$. alba samples. No significant difference between the wood types was apparent. 
The micrographs of samples prepared via dip-coating (Fig. 9) and spin-coating (Fig. 10) showed some beads on wood surface. There are number of agglomerates on the wood surface that had been treated with higher concentrations of 5\% and $7 \%$. Similarly, Ashori and Nourbakhsh (2011) reported that nanoclay filled pores and observed beads on wood surface. It was also reported that nanoclays fill nanocomposite pores, producing fewer pores compared to control treatment (Islam et al. 2017). The results showed bonds between nanoclay and zycosil in bead form for both methods. There were no beads on the surface of control samples. Thus, nanoclay was distributed well on the wood surface.

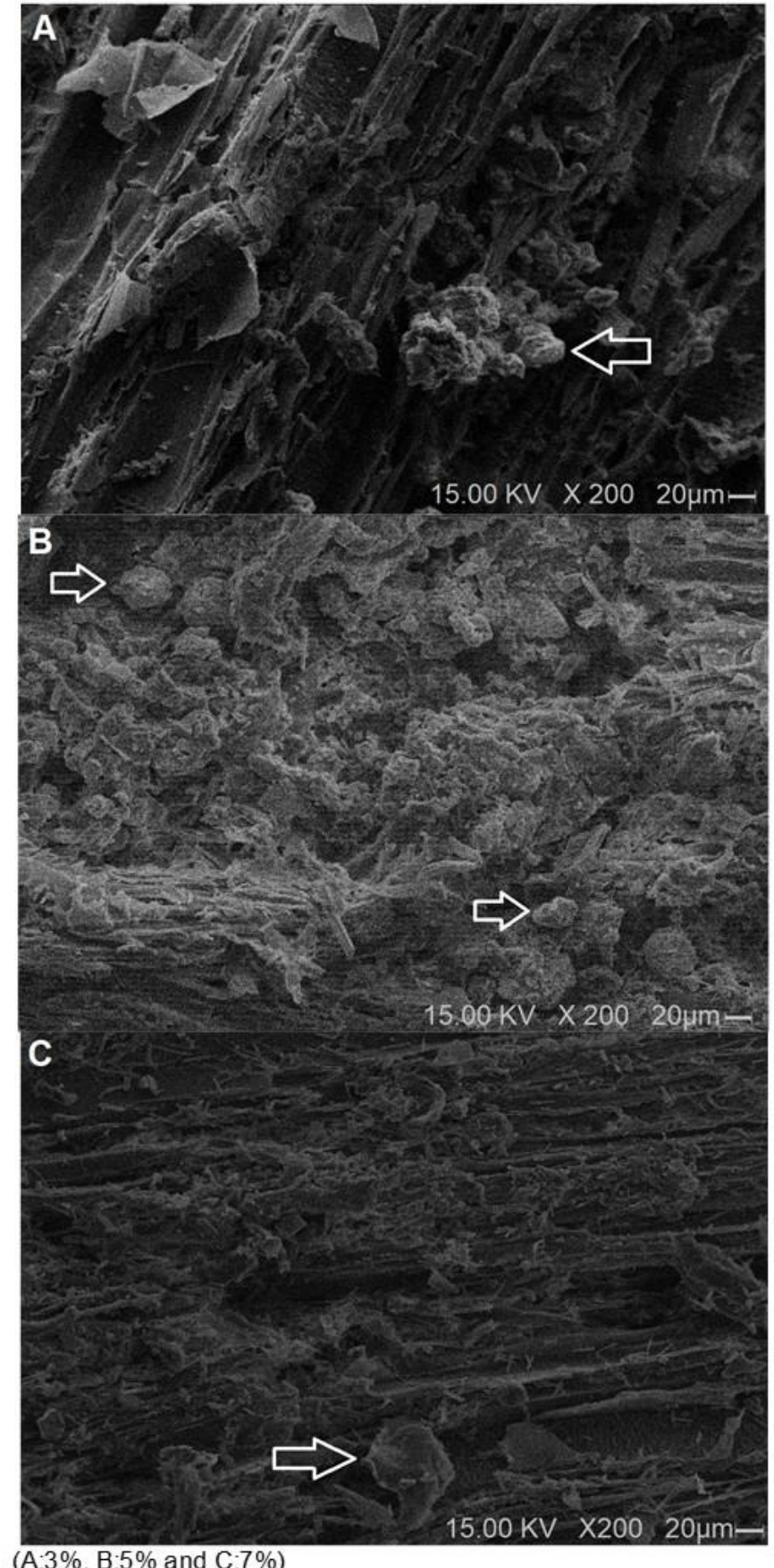

Fig. 9. SEM of $P$. nigra samples coated with dip-coating method. White arrows show beads that indicate connection between nanoclay and zycosil on the wood. 


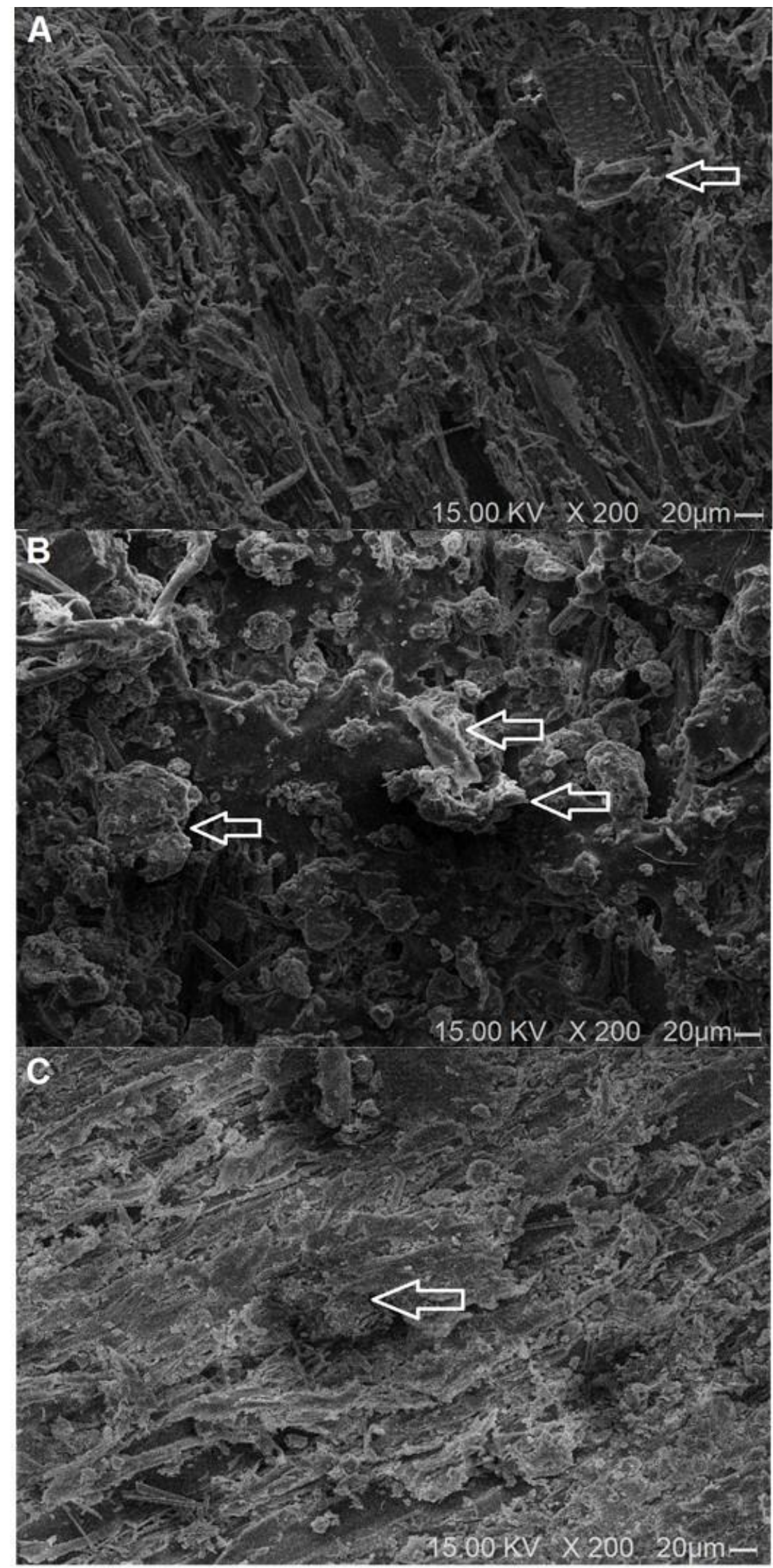

(A:3\%, B:5\% and C: $7 \%$ )

Fig. 10. SEM of $P$. nigra samples coated with spin-coating method. White arrows show beads that indicate connection between nanoclay and zycosil on the wood surface. 


\section{CONCLUSIONS}

1. The results for X-ray diffraction (XRD) and scanning electron microscopy (SEM) showed that nanoclay particles and zycosil were positioned on wood surface.

2. The results showed that increasing nanoclay particles improved performance parameters, and wood pores were filled with nanoclay, which resulted in increased hydrophobic properties.

3. The A. alba wood had better efficiency than the control P. nigra control wood, but coating $P$. nigra with nanoclay improved its efficiency.

4. Increasing concentration of nanoclay particle as coating increased flexural strength and density.

\section{REFERENCES CITED}

Alamri, H., and Low, I. M. (2013). "Effect of water absorption on the mechanical properties of nanoclay filled recycled cellulose fiber reinforced epoxy hybrid nanocomposites," Composites: Part A 44, 23-31. DOI: 10.1016/j.compositesa. 2012.08.026

Alimohamadi, A., Asadi, F., and Aghdaei, R. T. (2012). "Genetic diversity in Populus nigra plantations from west of Iran," Annals Forestry Research 56(1), 165-178.

Anwar, U. M. K., Alia-Syahirah, Y., Tumirah, K., Hamdan, H., and Lee, S. H. (2019). "Effects of nanoclay contents on the properties of water-based coating," Journal of Tropical Forest Science 31, 353-61.

Ashori, A., and Nourbakhsh, A. (2011). "Preparation and characterization of polypropylene/wood flour/nanoclay composites," European Journal of Wood Production 69, 663-666. DOI: 10.1007/s00107-010-0488-9

ASTM D7334-08 (2013). "Standard practice for surface wettability of coatings, substrates and pigments by advancing contact angle measurement," ASTM International, West Conshohocken, PA, USA.

ASTM D-D/D0143-94 (1999) . "Standard test method for evaluating properties of wood-base fiber and particle panel materials," ASTM International, West Conshohocken, PA, USA.

ASTM C128-04a (2004). "Standard test method for density, relative density (specific gravity), and absorption of fine aggregate," ASTM International, West Conshohocken, PA, USA.

Chang, H., Tu, K., Wang, X., and Liu, J. (2015). "Facile preparation of stable super hydrophobic coatings on wood surfaces using silica-polymer nanocomposites," BioResources 10(2), 2585-2596. DOI: 10.15376/biores.10.2.2585-2596

Devi, R. R., and Maji, T. K. (2013). "In situ polymerized wood polymer composite: effect of additives and nanoclay on the thermal and mechanical properties," Materials Research 16(4), 954-963. DOI: 10.1590/S1516-14392013005000071

Ha, S. R., Rhee, K. Y., Park, S. J., and Lee, J. H. (2010). "Temperature effects on the fracture behaviour and tensile properties of silane-treated clay/epoxy nanocomposites," Composites Part B: Engineering 41(8), 602-607. DOI: 10.1016/j.compositesb.2010.09.015 
Hazarika, A., and Maji, T. K. (2014). "Properties of soft wood polymer composites impregnated with nanoparticles and melamine formaldehyde furfuryl alcohol copolymer," Polymer Engineering Science 54(5), 1019-1029.

Hosseyni, M. J. M., Rahimi, S., Rahimi, S., and Faezipour, M. M. (2014). "Effect of nanoclay particles on the properties of particle boards," Journal of Basic Applied Science Research 4(3), 280-287.

Hwang, S. S., Liu, S. P., Hsu, P. P., Yeh, J. M., Chang, K. C., and Lai, Y. Z. (2010). "Effect of organoclay on the mechanical/thermal properties of microcellular injection molded PBT-clay nanocomposites," International Communication Heat Mass Transfer 37(8), 1036-1043. DOI: 10.1016/j.icheatmasstransfer.2010.06.010

Islam, H. R., Hamdan, S., Rusop, M., and Rahman, R. (2013). "Mechanical and Morphological properties of tropical wood polymer nanocomposite (WPNC)," Advanced Materials Research 667, 200-205. DOI: 10.4028/www.scientific.net/AMR.667.200

Kamal, M. R., Calderon, J. U., and Lennox, B. R. (2009). "Surface energy of modified nanoclays and its effect on polymer/clay nanocomposites," Journal of Adhesion Science and Technology 23, 663-688. DOI: 10.1163/156856108X379164.

Landry, V., Blanchet, P., and Riedl, B. (2010). "Mechanical and optical properties of clay-based nanocomposites coatings for wood flooring," Progress in Organic Coatings 67, 381-388.

Mandal, M., Halim, Z., and Maji, T. K. (2020). "Mechanical, moisture absorption, biodegradation and physical properties of nanoclay-reinforced wood/plant oil composites," SN Applied Sciences 2, 250. DOI: 10.1007/s42452-020-1984-0

Mantanis, G. I., and Papadopoulos, A. N. (2010). "The sorption of water vapour of wood treated with a nanotechnology compound," Wood Science and Technology 44(3), 515-522. DOI: 10.1007/s00226-010-0326-6

Petric, M. (2013). "Surface modification of wood: A critical review," Reviews of Adhesion and Adhesives 2, 216-247. DOI: 10.7569/RAA.2013.097308.

Scriven, L. E. (2011). "Physics and applications of DIP coating and spin coating," MRS Online Proceedings Library Archive 121, 717-725. DOI: 10.1557/PROC121-717.

Taghiyari, H. R. (2013). "Nano-zycosil in MDF: Gas and liquid permeability," European Journal of Wood and Wood Products 71, 353-360. DOI: 10.1007 /s00107-013-0691-6.

Teng, T. J., Nasir Mat Arip, M., Sudesh, K., and Nemoikina, A. (2018). "Conventional technology and nanotechnology in wood preservation: A review," BioResources 13(4), 9220-9252. DOI: 10.15376/biores.13.4.9220-9252.

Wang, T., Sun, H., Long, J., Wang, Y.Z., and Schiraldi, D. (2016). "Biobased poly (furfuryl alcohol)/clay aerogel composite prepared by a free-drying process," ACS Sustainable Chemistry \& Engineering 4 (5), 2601-2605. DOI:

10.1021/acssuschemeng.6b00089.

Wegner, T., Skog, K. E., Ince, P. J., and Michler, C. J. (2012). "Uses and desirable properties of wood in the $21^{\text {st }}$ century," Journal of Forestry 108(4), 165-173.

Zaidi, S. J., Fadhillah, F., Saleem, H., Hawari, A., and Benamor, A. (2019). "Organically modified nanoclay filled thin-film nanocomposite membranes for reverse osmosis application," Materials 12(22), 3803. DOI: 10.3390/ma12223803. 
Zainuddin, S., Hosur, M. V., Zhou, Y., Narteh, A. T., Kumar, A., and Jeelani, S. (2010). "Experimental and numerical investigations on flexural and thermal properties of nanoclay-epoxy nanocomposites," Material Science \& Engineering A 527(29-30), 7920-7926. DOI: 10.1016/j.msea.2010.08.078.

Article submitted: June 4, 2020; Peer review completed: August 15, 2020; Revised version received and accepted: August 25, 2020; Published: September 4, 2020.

DOI: $10.15376 /$ biores. 15.4.8026-8038 